\section{(- OPEN ACCESS}

\title{
Non-alcoholic fatty liver disease: a practical approach to treatment
}

\author{
J K Dyson, ${ }^{1}$ Q M Anstee, ${ }^{1,2}$ S McPherson ${ }^{1,2}$
}

\begin{abstract}
${ }^{1}$ Liver Unit, Freeman Hospital, Newcastle Upon Tyne Hospitals NHS Foundation Trust, Newcastle upon Tyne, UK ${ }^{2}$ Institute of Cellular Medicine, Newcastle University, Newcastle upon Tyne, UK
\end{abstract}

\section{Correspondence to}

Dr Jessica Dyson, Liver Unit, Freeman Hospital, Newcastle upon Tyne Hospitals NHS Foundation Trust, High Heaton, Newcastle upon Tyne, NE77DN, UK; jessicadyson@doctors.org.uk

Received 12 October 2013 Revised 26 December 2013 Accepted 1 January 2014 Published Online First 22 January 2014

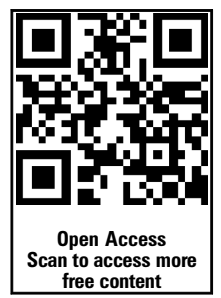

CrossMark

To cite: Dyson JK, Anstee QM, McPherson S. Frontline Gastroenterology 2014:5:277-286.

\begin{abstract}
Non-alcoholic fatty liver disease (NAFLD) affects up to a third of the population in many developed countries. Between $10 \%$ and $30 \%$ of patients with NAFLD have non-alcoholic steatohepatitis (NASH) that can progress to cirrhosis. There are metabolic risk factors common to both NAFLD and cardiovascular disease, so patients with NASH have an increased risk of liver-related and cardiovascular death. Management of patients with NAFLD depends largely on the stage of disease, emphasising the importance of careful risk stratification. There are four main areas to focus on when thinking about management strategies in NAFLD: lifestyle modification, targeting the components of the metabolic syndrome, liver-directed pharmacotherapy for high risk patients and managing the complications of cirrhosis.
\end{abstract}

\section{INTRODUCTION}

Non-alcoholic fatty liver disease (NAFLD) is now the commonest cause of chronic liver disease in many developed countries. ${ }^{1} \mathrm{Up}$ to a third of the population have evidence of steatosis on imaging, ${ }^{2} 3$ with the majority (70\%-90\%) having simple steatosis. However, $10 \%-30 \%$ of subjects with NAFLD have non-alcoholic steatohepatitis (NASH) that can progress to cirrhosis, which puts patients at risk of liver-related complications. ${ }^{4-6}$ Due to the metabolic risk factors that are common to both NAFLD and cardiovascular disease, patients with NASH have an increased risk of cardiovascular death as well as liver-related mortality. ${ }^{7}$ In the first part of this review, we discussed the diagnosis and staging of patients with NAFLD and the importance of risk stratification. ${ }^{9}$ Here we will discuss the management of patients with NAFLD.

\section{PRINCIPLES OF MANAGEMENT OF NAFLD}

Management of patients with NAFLD depends largely on the stage of disease, emphasising the importance of careful risk stratification. ${ }^{10}$ There are four main areas to focus on when thinking about management strategies in NAFLD: lifestyle modification, targeting the components of the metabolic syndrome, liver-directed pharmacotherapy for high risk patients and managing the complications of cirrhosis (figure 1).

All patients with NAFLD require advice about lifestyle modification aimed at weight loss and increased physical activity, as well as treatment of any associated metabolic risk factors (diabetes, hypertension and dyslipidaemia). For patients with simple steatosis, which carries a relatively benign liver-related prognosis, this can be done in a primary care setting. Patients with steatohepatitis and fibrosis are at highest risk of developing progressive liver disease so require more aggressive lifestyle modification and if this fails can be considered for liver-directed pharmacotherapy with pioglitazone or vitamin $\mathrm{E}$. For patients who have progressed to cirrhosis, surveillance for hepatocellular carcinoma (HCC) is essential and some treatments have been shown to reduce the risk of HCC. Interventions for the treatment of NAFLD are summarised in table 1 .

\section{LIFESTYLE MODIFICATION}

Lifestyle modification aimed at weight loss and increased physical activity is vital in managing all patients with NAFLD irrespective of their underlying liver histology. Patients should be encouraged to avoid a sedentary lifestyle by increasing daily activities, undertaking regular exercise and eating healthily. Overall, lifestyle 


\section{Managing \\ complications of \\ cirrhosis \\ Liver-directed \\ Pharmacotherapy \\ Targeting components of metabolic syndrome \\ Lifestyle Modification}

Figure 1 Management strategies in non-alcoholic fatty liver disease (NAFLD).

interventions including behavioural, dietary and exercise changes can be very effective in reducing body weight. In one study, patients who received dietary advice and undertook $200 \mathrm{~min}$ moderate physical activity per week for 48 weeks had an overall 9.3\% reduction in body weight (versus $0.2 \%$ in the control arm) and had improvement in hepatic steatosis and inflammation on liver biopsy. ${ }^{12}$

\section{Diet}

The optimum diet to treat NAFLD is not known. Until further evidence is available, a calorie restricted diet $(600 \mathrm{Kcal}$ less than a person needs to remain at the same weight) should be recommended aiming to lose $0.5-1 \mathrm{~kg}$ per week until the target weight is achieved. ${ }^{11}$ Patients with NAFLD should be advised to avoid saturated fats, simple carbohydrates and sweetened drinks. ${ }^{25}{ }^{26} \mathrm{~A}$ 'fast food diet' (high in cholesterol, saturated fats and fructose) is associated with progressive fibrosis in mice models. ${ }^{27}$

A Mediterranean diet (high in monounsaturated fatty acids), as compared with a diet low in fat and high in carbohydrates, has been shown to reduce hepatic steatosis and improve insulin sensitivity in non-diabetic subjects with NAFLD. ${ }^{28}$ Dietary supplementation with $\omega-3$ polyunsaturated fatty acids (n-3 PUFAs) has also been shown to decrease liver fat, ${ }^{29}$ so fish oil supplementation could be a simple therapeutic option but further studies are needed.

Intensive 12-month dietician-led lifestyle interventions are more effective than standard care for patients with NAFLD in terms of weight loss (5.6 vs $0.6 \mathrm{~kg}$ ) and achieving remission of NAFLD (64\% vs $20 \%$ ). ${ }^{30}$ Previous studies have shown that $>7 \%{ }^{12}$ and $\geq 9 \%{ }^{13}$ loss of body weight was associated with reduced steatosis, hepatocellular injury and hepatic inflammation. The optimum amount of weight loss to reduce fibrosis is not known, but studies in subjects undergoing bariatric surgery where larger weight losses are seen (average reduction 30\% of Body Mass Index (BMI) at 5 years) indicate that fibrosis regression occurs in the majority (65\%), ${ }^{19}$ although minor increases in fibrosis

Table 1 Summary of management of NAFLD

\begin{tabular}{|c|c|c|}
\hline Treatment & Intervention/indication & Target/outcome \\
\hline$\overline{\text { Diet }}$ & $\begin{array}{l}\text { Calorie restricted diet (600 calories less than daily requirement) } \\
\text { Aim to lose } 0.5-1.0 \mathrm{~kg} / \text { week }^{11} \\
\text { Avoid saturated fats, simple carbohydrates and sweetened drinks } \\
\text { Aim to lose }>10 \% \text { body weight and maintain loss }\end{array}$ & $\begin{array}{l}>7 \% \%^{12} \text { and } \geq 9 \%{ }^{13} \text { loss of body weight reduces steatosis, } \\
\text { ballooning and hepatic inflammation }\end{array}$ \\
\hline Exercise & $\begin{array}{l}\text { Increasing physical activity } \\
\text { Reduce total sedentary time } \\
30 \text { min moderate exercise } 5 \times / \text { week } \\
\text { 'Aerobic', 'resistance' and 'high intensity' exercise are all effective } \\
\text { Aim >10 } 000 \text { steps/day (pedometer) }\end{array}$ & $\begin{array}{l}\text { Lower levels of steatosis }^{14} \\
\text { Aerobic exercise improves insulin sensitivity }{ }^{15} 16 \\
\text { Improved liver enzymes and reduced liver fat }{ }^{17} 18\end{array}$ \\
\hline $\begin{array}{l}\text { Orlistat (enteric lipase } \\
\text { inhibitor) }\end{array}$ & $\begin{array}{l}\text { Achieve weight loss in conjunction with lifestyle modification if } \\
\mathrm{BMl}>30 \mathrm{~kg} / \mathrm{m}^{2^{11}} \\
\text { Only continue if }>5 \% \text { loss of body weight in } 3 \text { months is } \\
\text { achieved }\end{array}$ & Improves ALT and steatosis ${ }^{13}$ \\
\hline Bariatric surgery & $\begin{array}{l}\text { Not a primary treatment for NASH } \\
\text { Treatment for obesity if BMl }>40 \mathrm{~kg} / \mathrm{m}^{2} \text { or between } 35 \text { and } \\
40 \mathrm{~kg} / \mathrm{m}^{2} \text { with other significant disease }\end{array}$ & $\begin{array}{l}\text { Improve insulin sensitivity and lipid profile } \\
\text { Reduced steatosis, steatohepatitis and fibrosis }{ }^{19}\end{array}$ \\
\hline & Consider as first-line option if BMI greater $>50 \mathrm{~kg} / \mathrm{m}^{211}$ & $\begin{array}{l}\text { Gastric bypass procedures are most effective in producing } \\
\text { sustained weight loss }{ }^{20}\end{array}$ \\
\hline Pioglitazone & $\begin{array}{l}\text { Recommended for patients with more aggressive NASH who have } \\
\text { failed lifestyle interventions }\end{array}$ & $\begin{array}{l}\text { Reduces hepatocellular injury and fibrosis }{ }^{21-23} \\
\text { Consider increased risk of congestive cardiac failure, bladder } \\
\text { cancer and reduced bone density }\end{array}$ \\
\hline Vitamin E & $\begin{array}{l}\text { Reserved for selected patients with more advanced precirrhotic } \\
\text { NASH who have failed lifestyle interventions }\end{array}$ & Improves steatohepatitis 2224 \\
\hline
\end{tabular}

ALT, alanine transaminase; BMI, body index mass; NAFLD, non-alcoholic fatty liver disease; NASH, non-alcoholic steatohepatitis. 
were seen 5 years post-bariatric surgery in $20 \%$ (>90\% of these were worsening from stage 0 to 1 ). ${ }^{31}$ Ideally, patients should be encouraged to lose $>10 \%$ (but more is probably better) of body weight and maintain the weight loss or bring their waist circumference or BMI into their ethnicity specific 'normal' range (eg, for Caucasians: waist circumference $<94 \mathrm{~cm}$ for men and $<80 \mathrm{~cm}$ for women or BMI $<25 \mathrm{~m} / \mathrm{kg}^{2}$ ).

\section{Exercise}

People with NAFLD engage in less physical activity than their healthy counterparts ${ }^{32} 33$ and higher levels of habitual physical activity are associated with lower levels of steatosis. ${ }^{14}$ Aerobic exercise increases skeletal muscle insulin sensitivity and as a result reverses one of the key pathophysiological mechanisms that causes NAFLD (insulin resistance). ${ }^{15}{ }^{16}$ Although the optimum exercise to treat NAFLD is not known, studies examining moderate intensity training, high intensity training and resistance exercise have shown improvement in liver enzymes and reduction in liver fat, independent of weight loss, but the effects on histology remain unknown. ${ }^{17} 1834$ Therefore, all patients with NAFLD should be advised to increase physical activity and undertake regular exercise. Until further evidence is available, one approach is to recommend $30 \mathrm{~min}$ of moderate exercise five times weekly. ${ }^{11} \mathrm{In}$ reality though, a significant proportion of patients with NAFLD do not comply with these recommendations. In such patients, the use of pedometers can be quite helpful. We recommend that patients increase their daily step count to $>10000$ steps/day.

\section{Orlistat as an aid to weight loss}

Orlistat is an enteric lipase inhibitor that leads to malabsorption of dietary fat and can aid weight loss in subjects with obesity in conjunction with lifestyle modification. One study demonstrated that orlistat treatment for NAFLD improved alanine transaminase (ALT) and steatosis, ${ }^{35}$ but a subsequent RCT conducted by Harrison et al showed that orlistat in combination with calorie restriction and vitamin E (800 IU/day) did not enhance weight loss, improve liver enzymes or improve histopathology compared with calorie restriction and vitamin $\mathrm{E}$. In that study, they found that $\geq 9 \%$ weight loss resulted in improved histology irrespective of whether they received orlistat or placebo. ${ }^{13}$ National Institute of Health and Care Excellence (NICE) guidelines ${ }^{11}$ for obesity recommend that orlistat can be considered as an aid to weight loss in subjects who have not achieved their target weight by lifestyle intervention and have a BMI $>30 \mathrm{~kg} / \mathrm{m}^{2}$, so it seems reasonable to consider this treatment in patients with obesity and NAFLD. If orlistat is initiated, only patients who achieve $>5 \%$ loss of body weight in 3 months should continue the medication. Treatment duration should not be greater than 1 year as there is potential for fat soluble vitamin deficiency if continued for longer.

\section{Bariatric surgery}

Bariatric surgery has an increasing role in the management of patients with obesity and the metabolic syndrome. Restrictive procedures such as the gastric band, gastric balloon and sleeve gastrectomy decrease stomach size leading to early satiety. Malabsorptive procedures such as gastric bypass limit the absorption of food. Weight loss after bariatric surgery has beneficial effects on the components of the metabolic syndrome including improving insulin sensitivity, lipid profile as well as reducing long-term mortality. ${ }^{20} 36$ It also has specific effects on liver histology including reduced steatosis, steatohepatitis and fibrosis. ${ }^{19}$ The majority of the histological benefits occur within the first year postsurgery. ${ }^{31}$ The optimum type of bariatric surgery for the treatment of NASH is not known. Although gastric bypass surgery produces the largest sustained weight loss compared with other bariatric procedures, Mathurin et al found no significant differences among the gastric band, bilio-intestinal and gastric bypass groups in terms of global NAFLD activity score (NAS), steatosis, inflammation or ballooning. ${ }^{31}$ As there is a lack of long-term outcome data about bariatric surgery as a specific treatment for NAFLD, bariatric surgery cannot be considered as a primary treatment for NASH. ${ }^{37}$ However, NICE guidance suggests that surgery should be considered as a treatment for obesity for patients with BMI $>40 \mathrm{~kg} / \mathrm{m}^{2}$ or between 35 and $40 \mathrm{~kg} / \mathrm{m}^{2}$ with other significant disease that could be improved with weight loss. All appropriate non-surgical measures must be tried first and patients must receive intensive specialist management and be prepared to commit to long-term follow-up. Surgery can be considered as a first-line option for the treatment of obesity in adults with a BMI greater than $50 \mathrm{~kg} / \mathrm{m}^{2} .^{11}$

Bariatric surgery should be avoided in subjects with advanced cirrhosis with portal hypertension as there is a risk of hepatic decompensation with the rapid weight loss. ${ }^{38}$ Patients with decompensated cirrhosis have particularly high mortality rates post-bariatric surgery compared with compensated cirrhotics and non-cirrhotic patients $(16.3 \%$ vs $0.9 \%$ and $0.3 \%$, respectively, $\mathrm{p}=0.0002) .{ }^{39}$ In carefully selected patients with ChildPugh A cirrhosis, gastric bypass and sleeve gastrectomy have been shown to achieve weight loss and improve obesity-related comorbidities. ${ }^{40}$ However, patients with cirrhosis should undergo bariatric surgery at centres that perform large numbers of these procedures. ${ }^{39}$

\section{Liver-directed pharmacotherapy}

For patients with biopsy-proven NASH, where lifestyle intervention has failed, liver-directed pharmacotherapy with pioglitazone or vitamin $\mathrm{E}$ can be considered.

Pioglitazone

Several studies have demonstrated benefit from the thiazolidinediones in patients with NASH both with 
and without diabetes. ${ }^{212241}$ Aithal et al showed that 12 months of treatment with pioglitazone $30 \mathrm{mg} /$ day reduced hepatocellular injury and fibrosis compared with placebo. $^{21}$ More recently, the PIVENS study showed significantly more patients receiving pioglitazone had resolution of steatohepatitis (a secondary endpoint) than with placebo $(47 \%$ vs $21 \% \mathrm{p}=0.001)$, although the treatment arm narrowly failed to meet the very strict primary endpoint (improvement in NAS $\geq 2$ with at least 1-point improvement in hepatocyte ballooning without increase in fibrosis score). ${ }^{22} \mathrm{~A}$ recent meta-analysis has demonstrated that pioglitazone treatment in NASH significantly improves steatosis, inflammation and to a lesser degree, fibrosis. ${ }^{23}$ While pioglitazone appears to be an effective treatment for NASH, there are also some concerns about its long-term safety. Treatment with pioglitazone is associated with weight gain $(4.7 \%$ in the PIVENS study $)^{22}$ and there have been reports of increased risk of congestive cardiac failure, ${ }^{42}$ bladder cancer ${ }^{43}$ and reduced bone density. ${ }^{44}$ However, a meta-analysis of 16390 patients with type 2 diabetes mellitus (T2DM) treated with pioglitazone demonstrated an $18 \%$ reduction in death, myocardial infarction and stroke. $^{45}$ Therefore, after assessing risk and benefit, treatment with pioglitazone can be recommended for patients with more aggressive NASH who have failed lifestyle interventions. ${ }^{46}$ Caution should clearly be exercised in patients with cardiac disease (a common comorbidity in patients with NAFLD) and echocardiography performed prior to considering treatment with pioglitazone. The optimum dose and duration of treatment are not known.

\section{Vitamin E}

Vitamin $\mathrm{E}$ is an antioxidant that has recently been shown to have beneficial effects on histology in nondiabetic patients with NASH. In the large PIVENS trial, significantly more patients had improvement in steatohepatitis following 96 weeks of vitamin E $800 \mathrm{IU} /$ day compared with placebo $(42 \%$ vs $19 \%$ $\mathrm{p}<0.001){ }^{22}$ This was confirmed in a study of childhood $\mathrm{NASH}$, where vitamin $\mathrm{E}$ was shown to reduce steatohepatitis in a subgroup who had follow-up liver biopsies. ${ }^{24}$ Although vitamin E looks like a promising treatment for NASH, there are concerns about the long-term effects of vitamin $\mathrm{E}$ with a meta-analysis showing a small overall increase in all-cause mortality at doses $>400 \mathrm{IU} /$ day. $^{47}$ It has also been reported that there might be an increased risk of haemorrhagic stroke $^{48}$ and prostate cancer ${ }^{49}$ with high dose treatment. Vitamin E has not been evaluated in patients with cirrhosis or diabetes and NASH. Therefore, it should currently be reserved for selected patients with more advanced pre-cirrhotic NASH who have failed lifestyle interventions. The optimum dose and duration of treatment are not known.

\section{TARGETING COMPONENTS OF} THE METABOLIC SYNDROME

Management of diabetes mellitus in patients with NAFLD Approximately $40 \%-50 \%$ of patients with NAFLD attending secondary care clinics have T2DM and the majority have evidence of insulin resistance. ${ }^{50} 51$ T2DM is associated with more progressive fibrosis in NASH. It is therefore essential that all patients with NAFLD are regularly screened for diabetes. Once diagnosed, diabetes should be managed initially with dietary intervention. Although metformin has not been shown to improve histology in NASH, it is recommended as the first-line pharmacological treatment for T2DM as it aids weight loss and reduces the risk of any diabetes-related endpoint, microvascular disease, myocardial infarction (large vessel disease) and all-cause mortality. ${ }^{52-54}$

Treatment of diabetes should be escalated if the glycosylated haemoglobin (HbA1c) rises to $>7.5 \%$. NICE guidelines suggest a sulfonylurea (such as gliclazide) as second-line treatment for subjects with T2DM. ${ }^{52}$ However, sulfonylureas increase insulin secretion and can cause weight gain, which might be detrimental in NAFLD. Therefore, the insulin sensitiser, pioglitazone, should be considered as a second-line agent in subjects with NASH as studies have demonstrated its potential to improve insulin sensitivity as well as reduce hepatic steatosis and inflammation in subjects with NASH and T2DM. ${ }^{22}{ }^{41}$ However, the potential risks of bladder cancer, increased bone loss and cardiac failure need to be considered.

Glucagon-like peptide-1 (GLP-1) analogues (such as liraglutide or exenatide) should be considered as an alternative to insulin as a third-line agent to control diabetes where the HbA1c is $>7.5 \%$ in subjects with obesity. GLP-1 is an incretin secreted by ileal L-cells dependent on the presence of food in the small intestine. It increases insulin sensitivity, inhibits gastric emptying and decreases food intake by increasing satiety in the brain. ${ }^{55}$ On average, they reduce HbA1c by $1 \%$ and patients frequently lose weight (overall average $3 \mathrm{~kg}$ ). In a meta-analysis of the phase III studies of liraglutide for the treatment of type 2 diabetes $(n=4442), 26$ weeks treatment with liraglutide $1.8 \mathrm{mg}$ was associated with an improvement in liver enzymes as well as a trend towards reduced steatosis measured by $\mathrm{CT}^{56}$ This effect appeared to be mediated by its effect on weight loss and glycaemic control. Studies are underway to determine the effect of liraglutide on liver histology. However, as with all the antidiabetic drugs, a careful assessment of the risk and benefits should be undertaken as there is recent evidence to suggest that GLP-1 agonists might induce pancreatitis (particularly in those with very high triglycerides) and increase the potential for pancreatic cancer. $^{55}$

Table 2 summarises the treatment of type 2 diabetes and the metabolic syndrome in NAFLD. 
Table 2 Treatment of type 2 diabetes and the metabolic syndrome in NAFLD

\begin{tabular}{|c|c|c|}
\hline Treatment & Indication & Outcome \\
\hline Dietary intervention & See table 1 & Escalate treatment if $\mathrm{HbA} 1 \mathrm{c}>7.5 \%$ \\
\hline Metformin & First-line treatment of T2DM & $\begin{array}{l}\text { Aids weight loss } \\
\text { Reduces risk of any diabetes-related endpoint, microvascular disease, myocardial } \\
\text { infarction (large vessel disease) and all-cause mortality }{ }^{52} 53 \\
\text { Reduced HCC risk }{ }^{57} 58\end{array}$ \\
\hline Pioglitazone & Second-line treatment of T2DM in NASH & $\begin{array}{l}\text { Improve insulin sensitivity and reduces hepatic steatosis/steatohepatitis }{ }^{41} \\
18 \% \text { reduction in death, myocardial infarction and stroke in T2DM } \\
\text { Consider risks of bladder cancer, }{ }^{43} \text { increased bone loss }{ }^{44} \text { and cardiac failure }{ }^{42}\end{array}$ \\
\hline GLP-1 analogue & Third-line treatment of T2DM in NASH & $\begin{array}{l}\text { Reduce } \mathrm{HbA} 1 \mathrm{c} \text { by } 1 \% \text { and average } 3 \mathrm{~kg} \text { weight loss } \\
\text { Improve liver enzymes and reduce steatosis } \\
\text { Risk of pancreatitis }\end{array}$ \\
\hline Insulin/sulfonylureas & Fourth-line treatment of T2DM in NASH & Lead to weight gain that can be detrimental in NAFLD \\
\hline
\end{tabular}

\section{Hypertension}

Approximately $70 \%$ of patients with NAFLD have hypertension $^{59} 60$ and so it is imperative to screen all patients. If the blood pressure is $>140 / 90 \mathrm{~mm} \mathrm{Hg}$, patients should be managed according to NICE hypertension guidelines. ${ }^{61}$ ACE inhibitors (ACEIs) or angiotensin receptor blockers (ARBs) are recommended first-line for patients less than 55 years old, but calcium channel blockers are recommended in people over 55 years and those of Afro-Caribbean origin. However, targeting the renin-angiotensin system (RAS) might be beneficial in all patients with NAFLD as the RAS plays a role in liver fibrogenesis and blocking the RAS reduces fibrosis in experimental models of hepatic fibrosis. ${ }^{62} 63$ A previous study of 54 hypertensive patients with NASH demonstrated that both telmisartan $20 \mathrm{mg}$ and valsartan $80 \mathrm{mg}$ improved transaminase levels and insulin sensitivity, and telmisartan also showed a significant decrease in NASH activity score and fibrosis. ${ }^{64}$ Further larger studies are needed to confirm these observations, but ACEI or ARBs seem a logical choice in the management of hypertension in subjects with NAFLD. They may also have the added benefit of reducing the incidence of T2DM. A previous meta-analysis of more than 100000 patients also showed a $20 \%$ reduction in the incidence of new onset diabetes with the use of ACEI or ARBs. ${ }^{65}$

\section{Dyslipidaemia}

Dyslipidaemia is very common in patients with NAFLD and the metabolic syndrome. Effective treatment of dyslipidaemias is vital in the management of NAFLD to reduce patients' cardiovascular risk profile. NICE guidelines ${ }^{66}$ recommend simvastatin treatment as primary prevention for cardiovascular disease in adults with $a \geq 20 \% 10$-year risk of developing cardiovascular disease (using a risk calculator such as the Framingham risk calculator). More aggressive lipid control is recommended for secondary prevention of cardiovascular disease, aiming for a total cholesterol $<4 \mathrm{mmol} / \mathrm{L}$. A meta-analysis confirmed that statin therapy safely reduces the 5 -year incidence of all-cause mortality, major coronary events, coronary revascularisation and stroke by about $20 \%$ per $\mathrm{mmol} / \mathrm{L}$ reduction in LDL cholesterol. ${ }^{67}$

Raised transaminases are frequently seen in patients receiving statins (usually due to coexistent NAFLD) but they are safe in patients with liver disease, and serious liver injury is rarely seen in clinical practice. ${ }^{46}$ In a large cardiovascular outcomes study, statins were shown to improve liver enzymes and cardiovascular outcomes in patients with raised liver function tests (LFTs) due to NAFLD. ${ }^{68}$

Table 3 summarises the management of hypertension and dyslipidaemia in NAFLD.

Table 3 Management of hypertension and dyslipidaemia in NAFLD

\begin{tabular}{|c|c|c|}
\hline Risk factor & Treatment/indication & Outcome \\
\hline Hypertension & $\begin{array}{l}\text { ACEI and ARBs first-line if BP }>140 / 90 \mathrm{~mm} \mathrm{Hg}^{61} \\
\text { Escalate treatment according to NICE hypertension } \\
\text { guidelines }\end{array}$ & $\begin{array}{l}\text { Blocking RAS reduces hepatic fibrosis }{ }^{62} 63 \\
\text { ARBs improve transaminase levels and insulin sensitivity } \\
20 \% \text { reduction in new onset T2DM with ACEl or ARBs }{ }^{65}\end{array}$ \\
\hline Dyslipidaemia & $\begin{array}{l}\text { Primary prevention with statin if } \geq 20 \% 10 \text {-year risk } \\
\text { of developing cardiovascular disease } 66 \\
\text { If secondary prevention, aim total cholesterol } \\
<4 \mathrm{mmol} / \mathrm{L}\end{array}$ & $\begin{array}{l}\text { Statins reduce } 5 \text {-year incidence of all-cause mortality, major coronary events, } \\
\text { coronary revascularisation and stroke by about } 20 \% \text { per mmol/L reduction in LDL } \\
\text { cholesterol }{ }^{67} \\
\text { May reduce incidence of } \mathrm{HCC}^{69}\end{array}$ \\
\hline
\end{tabular}

ACEI, ACE inhibitor; ARB, angiotensin receptor blocker; BP, blood pressure; HCC, hepatocellular carcinoma; LDL, low-density lipoprotein; NAFLD, nonalcoholic fatty liver disease; NASH, non-alcoholic steatohepatitis; T2DM, type 2 diabetes mellitus; RAS, renin-angiotensin system. 


\section{Obstructive sleep apnoea}

Due to the high prevalence of obesity in subjects with NAFLD, obstructive sleep apnoea (OSA) is very common and often unrecognised. OSA is associated with an increased risk of NAFLD as well as more advanced fibrosis due to NASH. ${ }^{70}$ Clinicians should have a high index of suspicion for OSA and can screen patients in the clinic using the STOP BANG questionnaire that encompasses eight factors: Snoring, Tiredness, Observed apnoeas, Elevated blood pressure, BMI (>35 kg/m2), Age (>50 years), Neck circumference $(>40 \mathrm{~cm})$ and Gender (male). Patients who score $\geq 3$ points (a point is given for each positive risk factor) have a high likelihood of having OSA. This questionnaire has $83.6 \%, 92.9 \%$ and $100 \%$ sensitivity for mild, moderate and severe sleep apnoea, respectively. ${ }^{71}$ It is not known whether treatment of OSA slows or halts progression of fibrosis in NASH.

\section{MANAGING THE COMPLICATIONS OF CIRRHOSIS}

\section{Hepatocellular carcinoma}

Patients with NASH cirrhosis are at risk of the same complications of cirrhosis as with any other aetiology of liver disease. The yearly cumulative incidence of HCC is $2.6 \%$ per year in patients with NASH cirrhosis. $^{72}$ Therefore, surveillance with abdominal ultrasonography (USS) should be performed every 6 months. ${ }^{73}{ }^{74}$ In unselected cirrhotic patients, USS has a sensitivity ranging from $58 \%$ to $89 \%$ with a specificity $>90 \%$ when used as a surveillance test. ${ }^{75} 76$ Ultrasound can be technically difficult in obese patients so it is likely that ultrasound is less sensitive as a surveillance modality in patients with NAFLD, but currently there are no data to support the routine use of CT or MRI for surveillance. ${ }^{74}$ CT or MRI could be considered in subjects where ultrasound has failed to produce adequate examination of the liver, but these modalities have their own limitations in obese patients.

$\alpha$-Fetoprotein is a tumour biomarker and has recently been removed from the European guidelines but is still widely used in clinical practise alongside 6-monthly ultrasound. Although rare, HCC can occur on a background of non-cirrhotic NAFLD. ${ }^{77}$

There is a clear association between obesity and malignancy $^{78}$ and hyperinsulinaemia is well recognised as an independent risk factor for many malignancies. ${ }^{79} 80$ Aberrant genes involved in metabolic pathways, such as the AMP-activated protein kinase (AMPK)-LKB1 pathway, are emerging as therapeutic targets in cancer treatment. $^{81}$ Metformin acts by inhibiting hepatic glucose production through an LKB1-AMPK-mediated mechanism. There is emerging evidence that metformin reduces the risk of cancer (including HCC) in patients with diabetes in a dose-dependent manner. ${ }^{57}$ The mechanisms of the anticancer effects of metformin may include triggering of the LKB1-mediated AMPK pathway, resulting in cancer cell death under conditions of nutrient deprivation, ${ }^{82} 83$ and reducing proliferation of cancer cell lines. ${ }^{83}$

Donadon et al found that metformin treatment was associated with a statistically significant reduction of HCC risk (OR 0.33; CI 0.1 to $0.7, p=0.006$ ) in diabetic patients. ${ }^{84}$ The benefit of metformin was confirmed by Hassan et al who found the use of metformin or thiazolidinediones in diabetic patients was associated with a 70\% risk reduction of HCC compared with the use of insulin or sulfonylureas. ${ }^{85} \mathrm{~A}$ recent large Taiwanese nationwide case-control study demonstrated a $7 \%$ risk reduction per year for HCC in diabetics treated with metformin (adjusted $\mathrm{OR}=0.93$, 95\% CI 0.91 to $0.94, \mathrm{p}<0.0001){ }^{58}$

There is also evidence that statins might reduce the incidence of HCC. An American case-control study examining HCC in diabetic patients found an adjusted OR for statin use of 0.74 (95\% CI 0.64 to 0.87$)$. There were no significant associations with non-statin cholesterol- or triglyceride-lowering medications. ${ }^{86} \mathrm{~A}$ Taiwanese population-based case-control study found an adjusted OR of 0.62 (95\% CI 0.42 to 0.91 ) for HCC in patients prescribed statins. ${ }^{87}$ Singh et al conducted a systematic review and meta-analysis and found that statin users were less likely to develop HCC than non-users (adjusted OR, 0.63; 95\% CI 0.52 to 0.76). The risk reduction was most marked in Asian populations but was also observed in Western populations. ${ }^{69}$

Statins appear to have anticancer effects through both 3-hydroxy-3-methyl-glutaryl-CoA (HMG-CoA) reductase dependent and HMG-CoA reductase independent pathways. They have a variety of actions including: anti-inflammatory and immunomodulatory effects, inhibiting downstream production of mediators of cell growth ${ }^{88}$ and promoting programmed cell death. ${ }^{89}$ Studies have shown that inactivation of Myc can induce remission of HCC and atorvastatin blocks Myc activation resulting in suppression of tumour growth. 9091

\section{Varices}

Cirrhotic patients with NASH are at risk of varices as with other liver diseases and their presence correlates with the severity of liver disease (40\%-44\% if ChildPugh grade A, 75\%-85\% if Child-Pugh grade C). ${ }^{92}$ Therefore, patients with NASH cirrhosis should undergo endoscopic screening for oesophageal and gastric varices at the time of diagnosis and at regular intervals according to British Society of Gastroenterology or American Association for the Study of Liver Diseases guidelines ${ }^{93} 94$ (see table 4).

\section{Osteoporosis and fracture risk}

Patients with cirrhosis are at increased risk of osteoporosis and fractures. Cirrhotic patients should have a dual x-ray absorptiometry scan to assess bone mineral density and have their fracture risk assessed using the FRAX tool (http://www.shef.ac.uk/FRAX/tool). The 
Table 4 Managing the complications of cirrhosis

\begin{tabular}{|c|c|c|}
\hline Complication & Risk & Management \\
\hline $\begin{array}{l}\text { Hepatocellular } \\
\text { carcinoma }\end{array}$ & Yearly cumulative incidence $2.6 \%$ per year $^{50}$ & 6 monthly abdominal USS $\pm \alpha$-fetoprotein \\
\hline Varices & $\begin{array}{l}40 \%-44 \% \text { if Child-Pugh grade } A \\
75 \%-85 \% \text { if Child-Pugh grade } C^{92}\end{array}$ & $\begin{array}{l}\text { Endoscopic surveillance and management according to BSG or } \\
\text { AASLD guidelines }{ }^{94} 93\end{array}$ \\
\hline Osteoporosis & $\begin{array}{l}\text { Cirrhotic patients are at increased risk of osteoporosis } \\
\text { and fractures } \\
\text { Larger studies assessing the effects of vitamin D } \\
\text { supplementation on BMD are lacking }\end{array}$ & $\begin{array}{l}\text { Correction of vitamin D insufficiency with oral daily vitamin } D_{3} \\
\text { and calcium }{ }^{95} \\
\text { Dual x-ray absorptiometry scan to assess BMD } \\
\text { Assess fracture risk using FRAX tool (http://www.shef.ac.uk/ } \\
\text { FRAX/tool) }\end{array}$ \\
\hline
\end{tabular}

AASLD, American Association for the Study of Liver Diseases; BMD, bone mineral density; BSG, British Society of Gastroenterology; USS, ultrasonography.

FRAX tool has an easy online link to the National Osteoporosis Guideline Group website which provides management advice according to the patient's risk of fracture. Table 4 summarises the management of the complications of NASH cirrhosis.

\section{Liver transplantation}

NASH cirrhosis is now the third commonest indication for liver transplantation in the USA and accounted for $12 \%$ of patients listed for transplantation in the UK in $2009 .{ }^{96}$ Patient and graft survival in liver transplantation for NASH are comparable with other indications. ${ }^{96} 97$ Although recurrence of NASH is common posttransplant, occurring in 4\%-25\% of patients, it does not appear to impact on graft survival. ${ }^{9899}$ Patients who are transplanted for NASH cirrhosis frequently have multiple cardiovascular risk factors that should be managed aggressively post-transplant to prevent cardiovascular-related mortality. ${ }^{100}$ UK guidelines on liver transplantation suggest that bariatric surgery can be considered at the time of liver transplantation for patients with NASH and morbid obesity. ${ }^{100}$

\section{Summary}

Lifestyle interventions aimed at weight loss and increased activity are essential for all patients with NAFLD and if sustained are effective in the treatment of NAFLD. For patients who fail lifestyle intervention, liver-directed pharmacotherapy with pioglitazone or vitamin $\mathrm{E}$ can be considered for those with advanced, but pre-cirrhotic, NASH. Features of the metabolic syndrome and cardiovascular risk factors are very common in NAFLD, so all patients should be screened for these and have them managed aggressively. For patients who develop advanced disease, they require surveillance for and management of the complications of cirrhosis (HCC, varices, osteoporosis).

Contributors JD, QA and SM have all contributed to this review. Competing interests None.

Provenance and peer review Not commissioned; externally peer reviewed.

Open Access This is an Open Access article distributed in accordance with the Creative Commons Attribution Non
Commercial (CC BY-NC 3.0) license, which permits others to distribute, remix, adapt, build upon this work non-commercially, and license their derivative works on different terms, provided the original work is properly cited and the use is noncommercial. See: http://creativecommons.org/licenses/by-nc/3.0/

\section{REFERENCES}

1 Bedogni G, Miglioli L, Masutti F, et al. Prevalence of and risk factors for nonalcoholic fatty liver disease: the Dionysos nutrition and liver study. Hepatology 2005;42:44-52.

2 Browning JD, Szczepaniak LS, Dobbins R, et al. Prevalence of hepatic steatosis in an urban population in the United States: Impact of ethnicity. Hepatology 2004;40:1387-95.

3 Wong VW, Chu WC, Wong GL, et al. Prevalence of non-alcoholic fatty liver disease and advanced fibrosis in Hong Kong Chinese: a population study using proton-magnetic resonance spectroscopy and transient elastography. Gut 2012;61:409-15.

4 Matteoni CA, Younossi ZM, Gramlich T, et al. Non alcoholic fatty liver disease: a spectrum of clinical and pathological severity. Gastroenterology 1999;116:1413-19.

5 Wanless IR, Lentz JS. Fatty liver hepatitis (steatohepatitis) and obesity: an autopsy study with analysis of risk factors. Hepatology 1990;12:1106-10.

6 Williams CD, Stengel J, Asike MI, et al. Prevalence of nonalcoholic fatty liver disease and nonalcoholic steatohepatitis among a largely middle-aged population utilizing ultrasound and liver biopsy: a prospective study. Gastroenterology 2011;140:124-31.

7 Ekstedt M, Franzen LE, Mathiesen UL, et al. Long-term follow-up of patients with NAFLD and elevated liver enzymes. Hepatology 2006;44:865-73.

8 Anstee QM, Targher G, Day CP. Progression of NAFLD to diabetes mellitus, cardiovascular disease or cirrhosis. Nat Rev Gastroenterol Hepatol 2013;10:330-44.

9 Dyson JK, Anstee QM, Mcpherson S. Non-alcoholic fatty liver disease: a practical approach to diagnosis and staging. Frontline Gastroenterol 2014;5:211-8.

10 Anstee QM, McPherson S, Day CP. How big a problem is non-alcoholic fatty liver disease? BMJ 2011;343:d3897.

11 NICE. NICE Clinical guidelines. CG43 Obesity: the prevention, identification, assessment and management of overweight and obesity in adults and children. In: Care NIfHaCEaNCCfP, ed., 2006.

12 Promrat K, Kleiner DE, Niemeier HM, et al. Randomized controlled trial testing the effects of weight loss on nonalcoholic steatohepatitis. Hepatology 2010;51:121-9. 
13 Harrison SA, Fecht W, Brunt EM, et al. Orlistat for overweight subjects with nonalcoholic steatohepatitis: a randomized, prospective trial. Hepatology 2009;49:80-6.

14 Perseghin G, Lattuada G, De Cobelli F, et al. Habitual physical activity is associated with intrahepatic fat content in humans. Diabetes Care 2007;30:683-8.

15 Kirwan JP, Solomon TP, Wojta DM, et al. Effects of 7 days of exercise training on insulin sensitivity and responsiveness in type 2 diabetes mellitus. Am J Physiol Endocrinol Metab 2009;297:E151-6.

16 Van Der Heijden GJ, Wang ZJ, Chu Z, et al. Strength exercise improves muscle mass and hepatic insulin sensitivity in obese youth. Med Sci Sport Exerc 2010;42:1973-80.

17 Thoma C, Day CP, Trenell MI. Lifestyle interventions for the treatment of non-alcoholic fatty liver disease in adults: a systematic review. J Hepatol 2012;56:255-66.

18 Hallsworth K, Fattakhova G, Hollingsworth KG, et al. Resistance exercise reduces liver fat and its mediators in non-alcoholic fatty liver disease independent of weight loss. Gut 2011;60:1278-83.

19 Mummadi RR, Kasturi KS, Chennareddygari S, et al. Effect of bariatric surgery on nonalcoholic fatty liver disease: systematic review and meta-analysis. Clin Gastroenterol Hepatol 2008;6:1396-402.

20 Sjostrom L, Lindroos AK, Peltonen M, et al. Lifestyle, diabetes, and cardiovascular risk factors 10 years after bariatric surgery. NEJM 2004;351:2683-93.

21 Aithal GP, Thomas JA, Kaye PV, et al. Randomized, placebo-controlled trial of pioglitazone in nondiabetic subjects with nonalcoholic steatohepatitis. Gastroenterology 2008;135:1176-84.

22 Sanyal AJ, Chalasani N, Kowdley KV, et al. Pioglitazone, vitamin $\mathrm{E}$, or placebo for nonalcoholic steatohepatitis. NEJM 2010;362:1675-85.

23 Boettcher E, Csako G, Pucino F, et al. Meta-analysis: pioglitazone improves liver histology and fibrosis in patients with non-alcoholic steatohepatitis. Aliment Pharmacol Ther 2012;35:66-75.

24 Lavine JE, Schwimmer JB, Van Natta ML, et al. Effect of vitamin $\mathrm{E}$ or metformin for treatment of nonalcoholic fatty liver disease in children and adolescents: the TONIC randomized controlled trial. JAMA 2011;305:1659-68.

25 Zivkovic AM, German JB, Sanyal AJ. Comparative review of diets for the metabolic syndrome: implications for nonalcoholic fatty liver disease. Am J Clin Nutr 2007;86:285-300.

26 Musso G, Gambino R, Pacini G, et al. Prolonged saturated fat-induced, glucose-dependent insulinotropic polypeptide elevation is associated with adipokine imbalance and liver injury in nonalcoholic steatohepatitis: dysregulated enteroadipocyte axis as a novel feature of fatty liver. Am J Clin Nutr 2009;89:558-67.

27 Charlton M, Krishnan A, Viker K, et al. Fast food diet mouse: novel small animal model of NASH with ballooning, progressive fibrosis, and high physiological fidelity to the human condition. Am J Physiol Gastrointest Liver Physiol 2011;301:G825-34.

28 Ryan MC, Itsiopoulos C, Thodis T, et al. The Mediterranean diet improves hepatic steatosis and insulin sensitivity in individuals with non-alcoholic fatty liver disease. J Hepatol 2013;59:138-43.

29 Parker HM, Johnson NA, Burdon CA, et al. Omega-3 supplementation and non-alcoholic fatty liver disease: a systematic review and meta-analysis. J Hepatol

2012;56:944-51.

30 Wong VW, Chan RS, Wong GL, et al. Community-based lifestyle modification programme for non-alcoholic fatty liver disease: a randomized controlled trial. J Hepatol 2013;59:536-42.

31 Mathurin P, Hollebecque A, Arnalsteen L, et al. Prospective study of the long-term effects of bariatric surgery on liver injury in patients without advanced disease. Gastroenterology 2009;137:532-40.

32 Zelber-Sagi S, Nitzan-Kaluski D, Goldsmith R, et al. Role of leisure-time physical activity in nonalcoholic fatty liver disease: a population-based study. Hepatology 2008;48:1791-8.

33 Hsieh SD, Yoshinaga H, Muto T, et al. Regular physical activity and coronary risk factors in Japanese men. Circulation 1998;97:661-5.

34 Little JP, Gillen JB, Percival ME, et al. Low-volume high-intensity interval training reduces hyperglycemia and increases muscle mitochondrial capacity in patients with type 2 diabetes. J Appl Physiol 2011;111:1554-60.

35 Zelber-Sagi S, Kessler A, Brazowsky E, et al. A double-blind randomized placebo-controlled trial of orlistat for the treatment of nonalcoholic fatty liver disease. Clin Gastroenterol Hepatol 2006;4:639-44.

36 Sjostrom L, Narbro K, Sjostrom CD, et al. Effects of bariatric surgery on mortality in Swedish obese subjects. NEJM 2007;357:741-52.

37 Chavez-Tapia NC, Tellez-Avila FI, Barrientos-Gutierrez T, et al. Bariatric surgery for non-alcoholic steatohepatitis in obese patients. Cochrane Database System Rev 2010:CD007340.

38 D'Albuquerque LA, Gonzalez AM, Wahle RC, et al. Liver transplantation for subacute hepatocellular failure due to massive steatohepatitis after bariatric surgery. Liver Transpl 2008;14:881-5.

39 Mosko JD, Nguyen GC. Increased perioperative mortality following bariatric surgery among patients with cirrhosis. Clin Gastroenterol Hepatol 2011;9:897-901.

40 Shimizu H, Phuong V, Maia M, et al. Bariatric surgery in patients with liver cirrhosis. Surg Obes Relat Dis 2013;9:1-6.

41 Belfort R, Harrison SA, Brown K, et al. A placebo-controlled trial of pioglitazone in subjects with nonalcoholic steatohepatitis. NEJM 2006;355:2297-307.

42 Lago RM, Singh PP, Nesto RW. Congestive heart failure and cardiovascular death in patients with prediabetes and type 2 diabetes given thiazolidinediones: a meta-analysis of randomised clinical trials. Lancet 2007;370:1129-36.

43 Piccinni C, Motola D, Marchesini G, et al. Assessing the association of pioglitazone use and bladder cancer through drug adverse event reporting. Diabetes Care 2011;34:1369-71.

44 Lecka-Czernik B. Bone loss in diabetes: use of antidiabetic thiazolidinediones and secondary osteoporosis. Curr Osteoporos Rep 2010;8:178-84.

45 Lincoff AM, Wolski K, Nicholls SJ, et al. Pioglitazone and risk of cardiovascular events in patients with type 2 diabetes mellitus: a meta-analysis of randomized trials. JAMA 2007;298:1180-8.

46 Chalasani N, Younossi Z, Lavine JE, et al. The diagnosis and management of non-alcoholic fatty liver disease: practice guideline by the American Gastroenterological Association, American Association for the Study of Liver Diseases, and American College of Gastroenterology. Gastroenterology 2012;142:1592-609. 
47 Miller ER 3rd, Pastor-Barriuso R, Dalal D, et al. Meta-analysis: high-dosage vitamin E supplementation may increase all-cause mortality. Ann Intern Med 2005;142:37-46.

48 Schurks M, Glynn RJ, Rist PM, et al. Effects of vitamin E on stroke subtypes: meta-analysis of randomised controlled trials. BMJ 2010;341:c5702.

49 Lippman SM, Klein EA, Goodman PJ, et al. Effect of selenium and vitamin $\mathrm{E}$ on risk of prostate cancer and other cancers: the Selenium and Vitamin E Cancer Prevention Trial (SELECT). JAMA 2009;301:39-51.

50 McPherson S, Stewart SF, Henderson E, et al. Simple non-invasive fibrosis scoring systems can reliably exclude advanced fibrosis in patients with non-alcoholic fatty liver disease. Gut 2010;59:1265-9.

51 McPherson S, Anstee QM, Henderson E, et al. Are simple noninvasive scoring systems for fibrosis reliable in patients with NAFLD and normal ALT levels?. Eur J Gastroenterol Hepatol 2013;25:652-8.

52 NICE. NICE clinical guidelines. CG87 Type 2 diabetes: The management of type 2 diabetes. In: NICE, ed., 2010.

53 Stratton IM, Adler AI, Neil HA, et al. Association of glycaemia with macrovascular and microvascular complications of type 2 diabetes (UKPDS 35): prospective observational study. BMJ 2000;321:405-12.

54 UK Prospective Diabetes Study (UKPDS) Group. Effect of intensive blood-glucose control with metformin on complications in overweight patients with type 2 diabetes (UKPDS 34). Lancet 1998;352:854-65.

55 Nauck MA. A critical analysis of the clinical use of incretin-based therapies: the benefits by far outweigh the potential risks. Diabetes Care 2013;36:2126-32.

56 Armstrong MJ, Houlihan DD, Rowe IA, et al. Safety and efficacy of liraglutide in patients with type 2 diabetes and elevated liver enzymes: individual patient data meta-analysis of the LEAD program. Aliment Pharmacol Ther 2013;37:234-42.

57 Bo S, Benso A, Durazzo M, et al. Does use of metformin protect against cancer in Type 2 diabetes mellitus? $J$ Endocrinol Invest 2012;35:231-5.

58 Chen HP, Shieh JJ, Chang CC, et al. Metformin decreases hepatocellular carcinoma risk in a dose-dependent manner: population-based and in vitro studies. Gut 2013;62:606-15.

59 Marchesini G, Bugianesi E, Forlani G, et al. Nonalcoholic fatty liver, steatohepatitis, and the metabolic syndrome. Hepatology 2003;37:917-23.

60 Dixon JB, Bhathal PS, O'Brien PE. Nonalcoholic fatty liver disease: predictors of nonalcoholic steatohepatitis and liver fibrosis in the severely obese. Gastroenterology 2001;121:91-100.

61 NICE. NICE clinical guidelines. CG127 Hypertension: Clinical management of primary hypertension in adults. In: NICE, ed., 2011.

62 Bataller R, Sancho-Bru P, Gines P, et al. Activated human hepatic stellate cells express the renin-angiotensin system and synthesize angiotensin II. Gastroenterology 2003;125:117-25.

63 Paschos P, Tziomalos K. Nonalcoholic fatty liver disease and the renin-angiotensin system: implications for treatment. World J Hepatol 2012;4:327-31.

64 Georgescu EF, Ionescu R, Niculescu M, et al. Angiotensin-receptor blockers as therapy for mild-to-moderate hypertension-associated non-alcoholic steatohepatitis. World J Gastroenterol 2009;15:942-54.
65 Al-Mallah M, Khawaja O, Sinno M, et al. Do angiotensin converting enzyme inhibitors or angiotensin receptor blockers prevent diabetes mellitus? A meta-analysis. Cardiology J 2010;17:448-56.

66 NICE. NICE clinical guidelines. CG67 Lipid modification: Cardiovascular risk assessment and the modification of blood lipids for the primary and secondary prevention of cardiovascular disease. In: NICE, ed., 2010.

67 Baigent C, Keech A, Kearney PM, et al. Efficacy and safety of cholesterol-lowering treatment: prospective meta-analysis of data from 90,056 participants in 14 randomised trials of statins. Lancet 2005;366:1267-78.

68 Athyros VG, Tziomalos K, Gossios TD, et al. Safety and efficacy of long-term statin treatment for cardiovascular events in patients with coronary heart disease and abnormal liver tests in the Greek Atorvastatin and Coronary Heart Disease Evaluation (GREACE) Study: a post-hoc analysis. Lancet 2010;376:1916-22.

69 Singh S, Singh PP, Singh AG, et al. Statins Are Associated With a Reduced Risk of Hepatocellular Cancer: a Systematic Review and Meta-analysis. Gastroenterology 2013;144:323-32.

70 Musso G, Cassader M, Olivetti C, et al. Association of obstructive sleep apnoea with the presence and severity of non-alcoholic fatty liver disease. A systematic review and meta-analysis. Obes Rev 2013;14:417-31.

71 Chung F, Yegneswaran B, Liao P, et al. STOP questionnaire: a tool to screen patients for obstructive sleep apnea.

Anesthesiology 2008;108:812-21.

72 Ascha MS, Hanouneh IA, Lopez R, et al. The incidence and risk factors of hepatocellular carcinoma in patients with nonalcoholic steatohepatitis. Hepatology 2010;51:1972-8.

73 Bruix J, Sherman M, American Association for the Study of Liver. Management of hepatocellular carcinoma: an update. Hepatology 2011;53:1020-2.

74 European Association For The Study Of The Liver, European Organisation For Research And Treatment Of Cancer. EASL-EORTC clinical practice guidelines: management of hepatocellular carcinoma. J Hepatol 2012;56:908-43.

75 Bolondi L. Screening for hepatocellular carcinoma in cirrhosis. J Hepatol 2003;39:1076-84.

76 Kim CK, Lim JH, Lee WJ. Detection of hepatocellular carcinomas and dysplastic nodules in cirrhotic liver: accuracy of ultrasonography in transplant patients. J Ultrasound Med 2001;20:99-104.

77 Kawada N, Imanaka K, Kawaguchi T, et al. Hepatocellular carcinoma arising from non-cirrhotic nonalcoholic steatohepatitis. J Gastroenterol 2009;44:1190-4.

78 Calle EE, Rodriguez C, Walker-Thurmond K, et al. Overweight, obesity, and mortality from cancer in a prospectively studied cohort of U.S. adults. NEJM 2003;348:1625-38.

79 Gunter MJ, Hoover DR, Yu H, et al. Insulin, insulin-like growth factor-I, and risk of breast cancer in postmenopausal women. J Natl Cancer Inst 2009;101:48-60.

80 Giovannucci E. Metabolic syndrome, hyperinsulinemia, and colon cancer: a review. Am J Clin Nutr 2007;86:s836-42.

81 Pollak M. Energy metabolism, cancer risk, and cancer prevention. Recent Results Cancer Res 2009;181:51-4.

82 Choi YK, Park KG. Metabolic roles of AMPK and metformin in cancer cells. Mol Cells 2013;36:279-87.

83 Zhou G, Myers R, Li Y, et al. Role of AMP-activated protein kinase in mechanism of metformin action. J Clin Invest 2001;108:1167-74. 
84 Donadon V, Balbi M, Ghersetti M, et al. Antidiabetic therapy and increased risk of hepatocellular carcinoma in chronic liver disease. World J Gastroenterol 2009;5:2506-11.

85 Hassan MM, Curley SA, Li D, et al. Association of diabetes duration and diabetes treatment with the risk of hepatocellular carcinoma. Cancer 2010;116:1938-46.

86 El-Serag HB, Johnson ML, Hachem C, et al. Statins are associated with a reduced risk of hepatocellular carcinoma in a large cohort of patients with diabetes. Gastroenterology 2009;136:1601-8.

87 Chiu HF, Ho SC, Chen CC, et al. Statin use and the risk of liver cancer: a population-based case-control study. Am J Gastroenterol 2011;106:894-8.

88 Demierre MF, Higgins PD, Gruber SB, et al. Statins and cancer prevention. Nat Rev Cancer 2005;5:930-42.

89 Wu J, Wong WW, Khosravi F, et al. Blocking the Raf/MEK/ ERK pathway sensitizes acute myelogenous leukemia cells to lovastatin-induced apoptosis. Cancer Res 2004;64:6461-8.

90 Shachaf CM, Kopelman AM, Arvanitis C, et al. MYC inactivation uncovers pluripotent differentiation and tumour dormancy in hepatocellular cancer. Nature 2004;431:1112-7.

91 Cao Z, Fan-Minogue H, Bellovin DI, et al. MYC phosphorylation, activation, and tumorigenic potential in hepatocellular carcinoma are regulated by HMG-CoA reductase. Cancer Res 2011;71:2286-97.

92 Zaman A, Becker T, Lapidus J, et al. Risk factors for the presence of varices in cirrhotic patients without a history of variceal hemorrhage. Arch Intern Med 2001;161:2564-70.

93 Garcia-Tsao G, Sanyal AJ, Grace ND, et al. Prevention and management of gastroesophageal varices and variceal hemorrhage in cirrhosis. Hepatology 2007;46:922-38.

94 Jalan R, Hayes PC. UK guidelines on the management of variceal haemorrhage in cirrhotic patients. British Society of Gastroenterology. Gut 2000;46(Suppl 3-4):III1-III15.

95 Collier JD, Ninkovic M, Compston JE. Guidelines on the management of osteoporosis associated with chronic liver disease. Gut 2002;50(Suppl 1):i1-9.

96 Charlton MR, Burns JM, Pedersen RA, et al. Frequency and outcomes of liver transplantation for nonalcoholic steatohepatitis in the United States. Gastroenterology 2011;141:1249-53.

97 Ratziu V, Bellentani S, Cortez-Pinto $\mathrm{H}$, et al. A position statement on NAFLD/NASH based on the EASL 2009 special conference. J Hepatol 2010;53:372-84.

98 Malik SM, Devera ME, Fontes P, et al. Recurrent disease following liver transplantation for nonalcoholic steatohepatitis cirrhosis. Liver Transpl 2009;15:1843-51.

99 Yalamanchili K, Saadeh S, Klintmalm GB, et al. Nonalcoholic fatty liver disease after liver transplantation for cryptogenic cirrhosis or nonalcoholic fatty liver disease. Liver Transpl 2010;16:431-9.

100 Newsome PN, Allison ME, Andrews PA, et al. Guidelines for liver transplantation for patients with non-alcoholic steatohepatitis. Gut 2012;61:484-500. 